\title{
14. Notes on Damaging Action of Crystalloiodinin upon Ehrlich Carcinoma Cells*)
}

\author{
By Sajiro Makino, ${ }^{* *)}$ Yanagi Kimura,**) \\ and Tosi IRIE***) \\ (Comm. by Yoshimaro TANAKA, M.J.A., Jan. 12, 1963)
}

A broad survey has for many years been continued in the field of cancer chemotherapy for the discovery of anti-tumor agents effective in damaging tumor cells and in a consequent regression of tumor growth. The present study deals with some tumor-damaging action of new antibiotics, crystalloiodinin A (iodinin) and B, which were originally isolated by Sasaki et al. (1959) from the culture medium of Brevibacterium crystalloiodinum grown in "miso" or bean paste. It was shown by Irie et al. (1960) that crystalloiodinin A was identical with iodinin (1, 6-di-hydroxyphenazine di-N-oxide), and crystalloiodinin B with 1, 6-di-hydroxyphenazine (Fig. 12).

Ehrlich carcinoma was transplanted for this experiment to mice of AKR, EM-agouti and em-brown strains. Crystalloiodinin A and $B$ were initially suspended with acetone and then diluted with saline solution to a concentration not exceeding 1 per cent acetone. The suspension was injected intraperitoneally to mice on the 7th day of tumor transfer at dosages of 5 and $10 \mathrm{mg} / \mathrm{Kg}$. Observations were carried out at appropriate intervals following the injection of the chemicals, based on cytological preparations stained with acetic dahlia (Makino 1957), May-Grünwald-Giemsa (Jacobson and Webb 1952), and Feulgen's method (Stowell 1945).

Crystalloiodinin A (iodinin): The action of crystalloiodinin A was rather drastic. Within 6 hours after application, almost all mitotic tumor cells showed abnormalities, such as stickiness, contraction, or scattering of the chromosomes at metaphase and lagging or sticky bridges of anaphase chromosomes, which led to subsequent damage of cells (Figs. 3-5). Many pycnotic nuclei together with cells with lobated nuclei appeared in samples taken 18 to 30 hours after application (Figs. 6 and 8).

Recovery of the tumor was observed in AKR and EM-agouti

*) The cytological effect of chemical on tumors, XX. Contribution No. 584 from the Zoological Institute, Faculty of Science, Hokkaido University, Sapporo, Japan. Supported by a grant to S. Makino from the Damon Runyon Memorial Fund for Cancer Research (DRG-563 B).

**) Department of Zoology.

***) Department of Chemistry. 


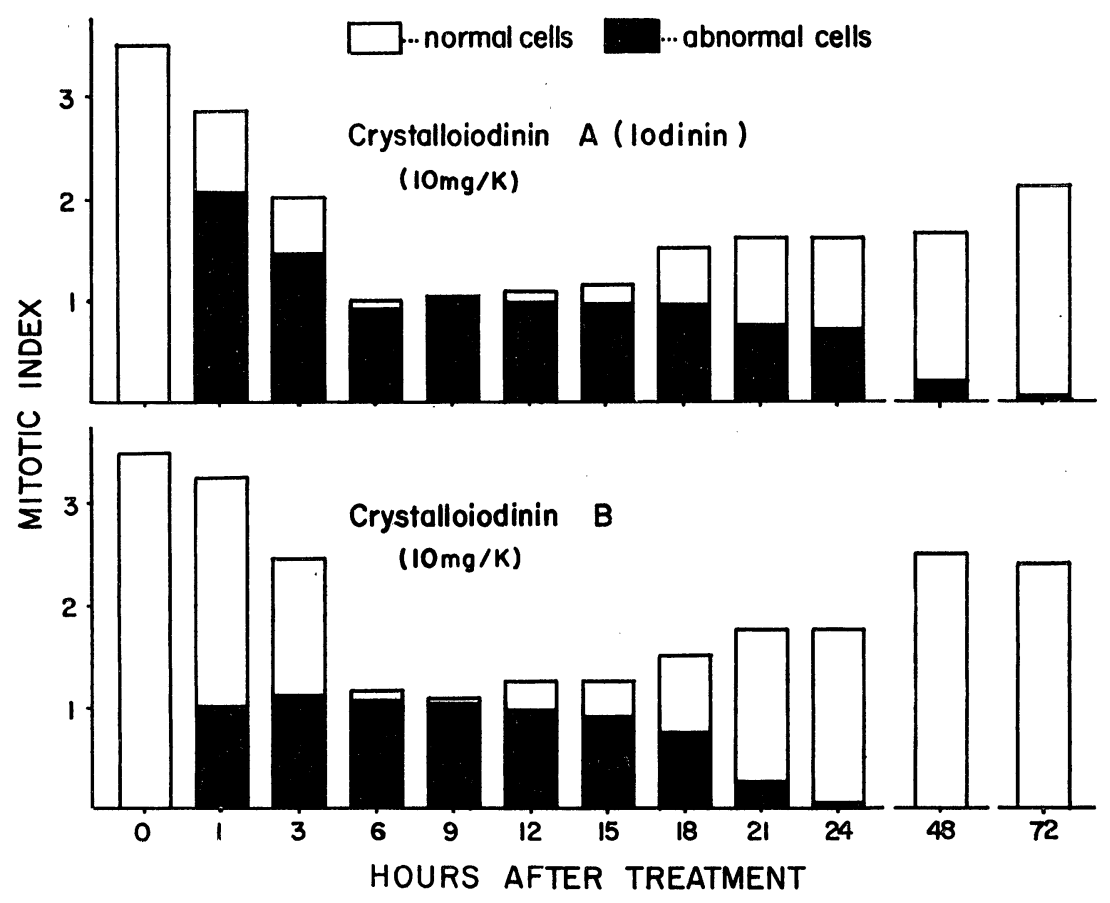

Fig. 1

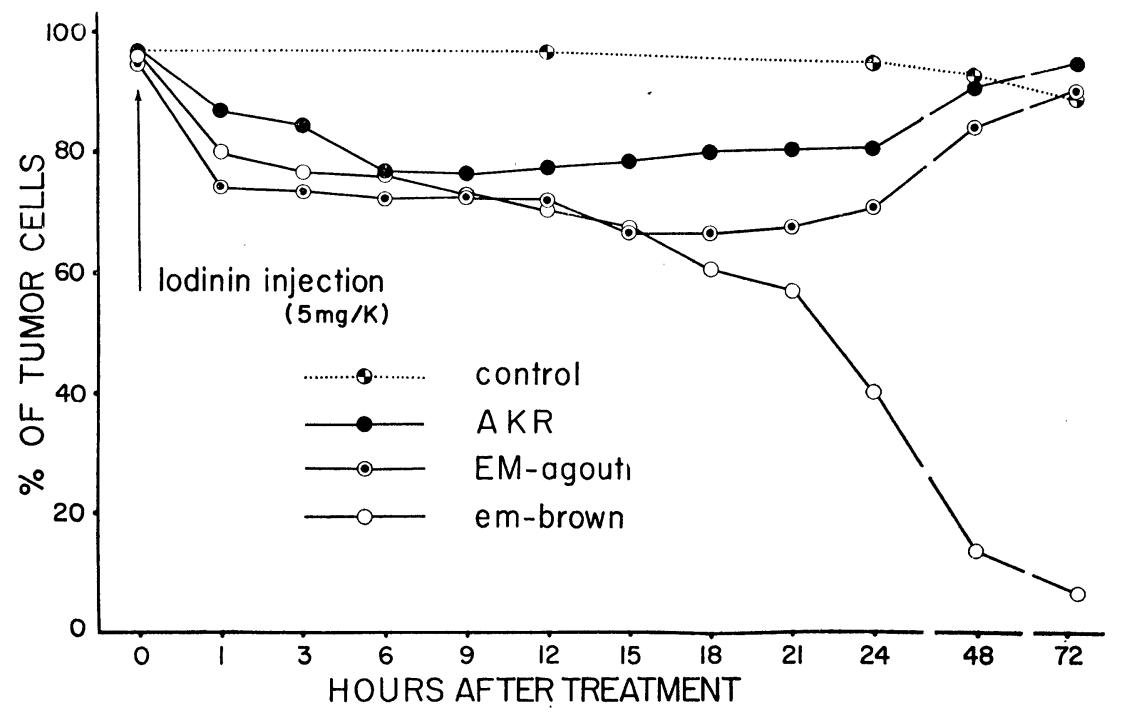

Fig. 2

specimens between 24 to 30 hours after chemical application. In embrown specimens, however, the tumor did not appear in most cases; 30-hour-samples showed tumor cells under damage, with a striking decrease of active tumor cells (Fig. 7). 
In tumor-bearing mice of AKR and EM-agouti strains, no remarkable prolongation of life span was obtained following the drug application; they lived as long as control mice did. However, in embrown tumor-mice treated with crystalloiodinin $\mathrm{A}$ the situation is different: 14 out of 17 tumor-mice survived more than 100 days, while the remaining three mice lived slightly longer than controls (Table I). Two out of 14 long-lived em-brown tumor-mice were sacrificed for biopsy: there were neither detectable tumor cells nor sign of metastasis in their body cavities.

Table I. Life span of tumor-bearing mice (Ehrlich carcinoma) after treatment with crystalloiodinin $\mathrm{A}$ (iodinin) and $\mathrm{B}$

\begin{tabular}{l|c|c|c|c}
\hline & \multicolumn{2}{|c|}{$\begin{array}{c}\text { Crystalloiodinin A-treatment } \\
(5 \mathrm{mg} / \mathrm{Kg})\end{array}$} & \multicolumn{2}{|c}{$\begin{array}{c}\text { Crystalloiodinin B-treatment } \\
(5 \mathrm{mg} / \mathrm{Kg})\end{array}$} \\
& No. of mice & Av. life span & No. of mice & Av. life span \\
\hline Control* & 21 & $16.7(16-19)$ & & \\
\hline AKR & 15 & $19.7(14-22)$ & 13 & $17.6(17-20)$ \\
\hline Em-agouti & 16 & $18.5(17-20)$ & 12 & $18.3(16-20)$ \\
\hline em-brown & $17\left[\begin{array}{c}3 \\
14\end{array}\right.$ & $28.0(24-30)$ & $100 \sim$ & $26.9(23-30)$ \\
\hline
\end{tabular}

* Control includes AKR, EM-agouti and em-brown mice. There was no difference between transplantability and tumor-takes among these strains of mice.

Crystalloiodinin B: It was found that cytologically the action of this drug upon tumor cells was generally similar to that of crystalloiodinin A. Cells in the course of mitosis were affected initially: under the influence they showed stickiness or contraction of the chromosomes at metaphase, anaphase bridges, and irregular spindles (Figs. 9-11). During a period of 12 to 18 hours after injection, cells showing pycnotic or lobated nuclei were seldom in occurrence. Regrowth of the tumor occurred without exception within 30 hours after the drug application. Therefore, no prolongation of life span was obtained in the crystalloiodinin B treated tumor-mice. All the tumor-bearing mice of AKR, EM-agouti and em-brown strains died 16 to 30 days following the application; the life-span of em-brown tumor-mice was somewhat longer than in the others (Table I).

Remarks. Makino (1957), working on the cytological effects of chemicals upon tumor cells, grouped the drugs into three categories: 1) agents exerting their influence on the nucleus proper, 2) agents which affect cytoplasmic components, and 3) those exerting their damaging effects on both nuclear and cytoplasmic components. 


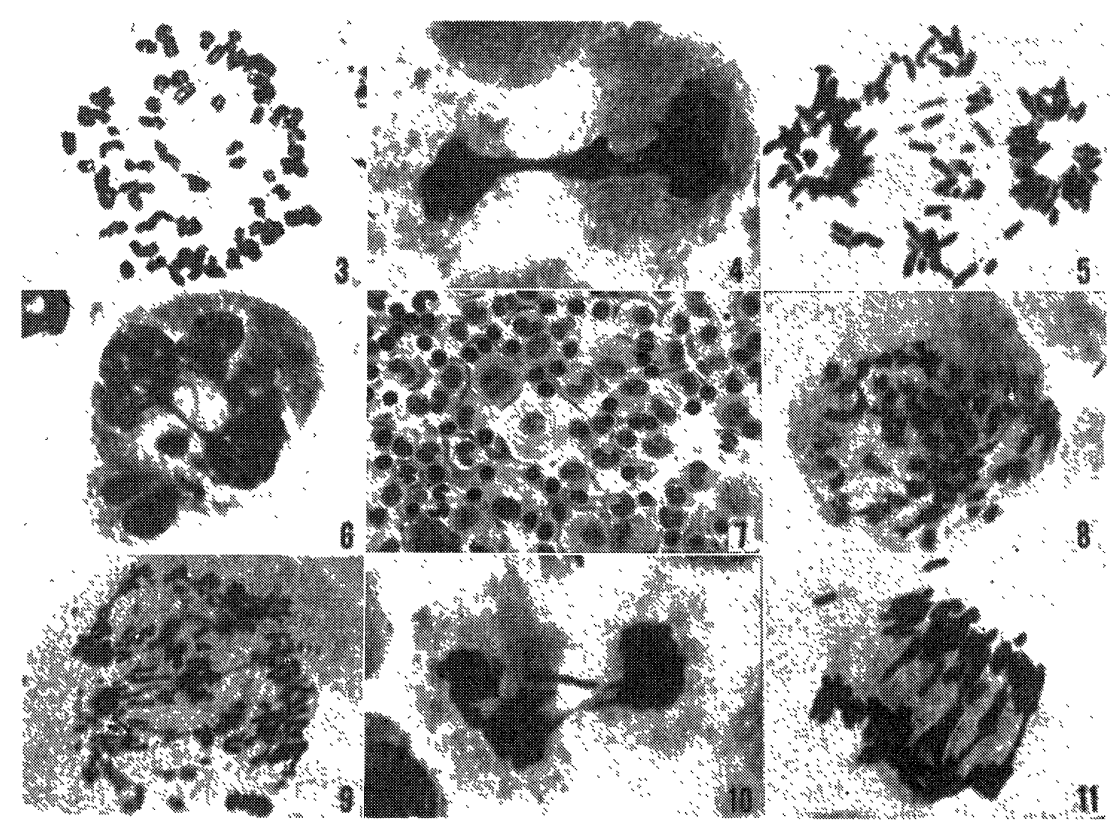

Figs. 3-8. Destructive changes of Ehrlich carcinoma cells following iodinintreatment $(10 \mathrm{mg} / \mathrm{kg})$. Fig. 3. Contraction of chromosomes at metaphase, 6-hour-treatment (Feulgen). $\times 1800 . \quad$ Fig. 4. Sticky bridges at anaphase, 6-hour-treatment (acetic dahlia). $\times 1500 . \quad$ Fig. 5. Lagging of chromosomes, 6-hour-treatment (acetic dahlia). $\times 1500$. Fig. 6. Lobated nuclei, 24-hourtreatment (acetic dahlia). $\times 1500$. Fig. 7. Increase in number of inflammatory cells in em-brown mice, 48-hour-treatment (acetic dahila). $\times 300$. Fig. 8 . Pycnotic aggregation of chromation, 24-hour-treatment (MGG). $\quad \times 1000$.

Figs. 9-11. Degenerative changes of Ehrlich carcinoma cells by the application of crystalloiodinin B $(10 \mathrm{mg} / \mathrm{kg}, 6$-hour-treatment). $\times 1500$. Fig. 9. Scattering of chromosomes at anaphase (MGG). Fig. 10. Sticky bridges at anaphase (acetic dahlia). Fig. 11. Spindle disturbance at anaphase (acetic dahlia).

Cytological abnormalities induced by crystalloiodinin A and B seem to be of similar nature to those of the first category, since the drugs attacked specifically cells in mitotic processes. They produced in affected cells stickiness and contraction of the chromosomes at metaphase, lagging or sticky bridges at anaphase, and abnormal spindles. It is then apparent that the two antibiotics produced damaging sequences of similar nature in tumor cells, so far as the Ehrlich carcinoma was concerned. It is further probable from their anti-tumor action that they are chemically very related to each other; the one being an N-oxide of the other (Fig. 12).

Specially interesting is the fact that within the scope of this experiment, the tumor reappeared in treated mice of AKR and EMagouti strains, whereas in em-brown tumor-mice the regrowth of 
tumor did not generally take place, particularly in the case of crystalloiodinin A. The em-brown mice are genetically closely related to EM-agouti mice: the former were produced originally in the senior author's animal house by means of brother-sister matings of hybrids between EM-agouti and EM-black mice. It was shown through in vitro and in vivo studies that the type of response to chemicals differed by different types of tissues (Makino and Cornman 1953, Kornofsky 1956). The consistent results of the present experiment indicate, in general, that the action of the drugs upon the Ehrlich tumor differs accoding to strains of tumor-bearing hosts.

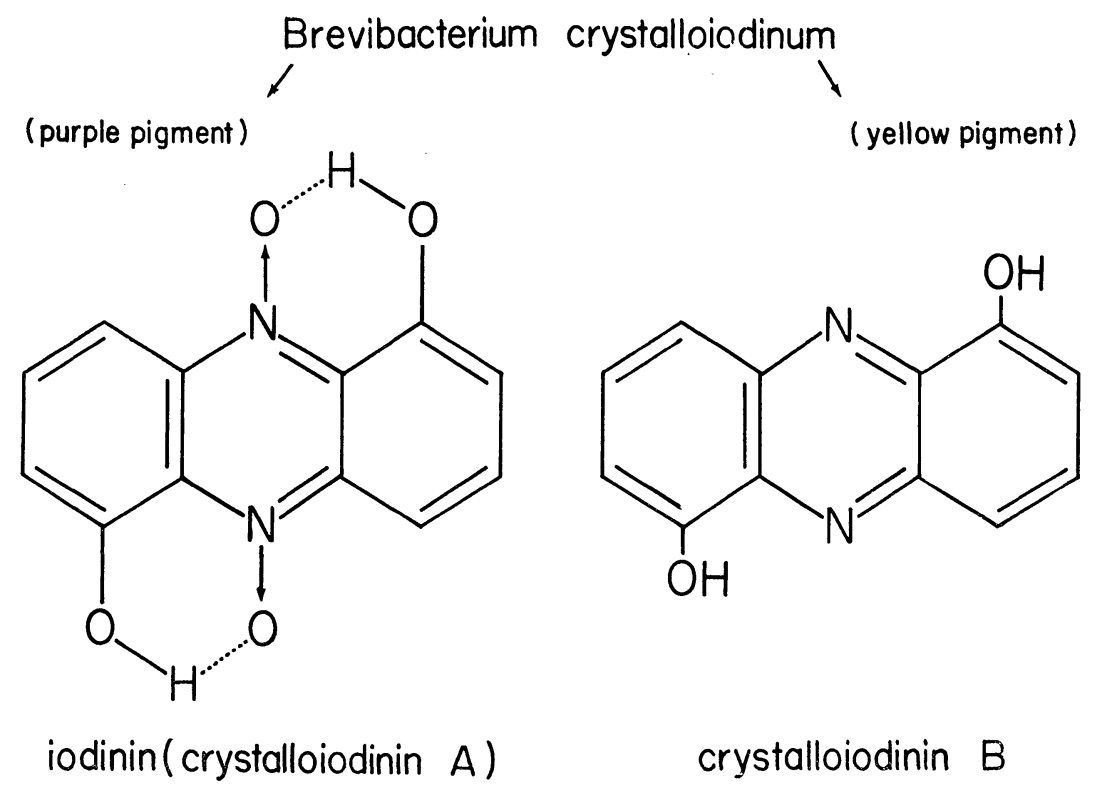

Fig. 12

In conclusion, the action of crystalloiodinin A (iodinin) and B was cytologically investigated in AKR, EM-agouti and em-brown mice bearing the Ehrlich ascites carcinoma. Cytological effects of the two antibiotics on tumor cells followed a similar damaging pattern: they attacked specifically cells in process of mitosis and produced stickiness, contraction or scattering of the chromosomes at metaphase, lagging or sticky bridges at anaphase, and abnormal spindle-formation. The drugs seemed to act upon the tumor in different manner in hosts of different strains. Particularly, crystalloiodinin A caused a striking prolongation of life span in treated em-brown tumor-mice.

The authors' cordial thanks are offered to Professor Yuji Sasaki and Dr. Hiroshi Sasaki, Department of Agricultural Chemistry, Hokkaido University for valuable advice. 
A support from the Chugai Pharmaceutical Co. Ltd., Tokyo is gratefully acknowledged here.

\section{References}

Irie, T., E. Kurosawa, and I. Nagaoka (1960): Bull. Chem. Soc. Jap., 33, 1057-1059. Jacobson, W., and M. Webb (1952): Exptl. Cell Res., 3, 163-183.

Kornofsky, D. A. (1956): Cancer Res., 16, 684-697.

Makino, S. (1957): Intern. Rev. Cytol., 6, 25-84.

Makino, S., and I. Cornman (1953): Cytologia, 18, 277-282.

Sasaki, Y., T. Yoshida, and H. Sasaki (1959): Abst. Meet. Soc. Agr. Chem. Jap. Tokyo, p. 35 .

Stowell, R. E. (1945): Stain Tech., 20, 45. 